\title{
Erector Spinae Plane Block for Open and Laparoscopic Liver Surgery: Two Case Reports
}

\author{
Jimmy Guan Cheng Lim* ${ }^{\circledR}$, Agnes Wanwei Huang ${ }^{\circledR}$, Kwee Lian Woon, Prit Anand Singh ${ }^{\circledR}$ \\ Department of Anaesthesia and Surgical Intensive Care, Changi General Hospital, Singapore \\ Email: *jimmy.lim.g.c@singhealth.com.sg
}

How to cite this paper: Lim, J.G.C., Huang, A.W., Woon, K.L. and Singh, P.A. (2020) Erector Spinae Plane Block for Open and Laparoscopic Liver Surgery: Two Case Reports. Open Journal of Anesthesiology, 10, 113-119.

https://doi.org/10.4236/ojanes.2020.104010

Received: March 13, 2020

Accepted: April 6, 2020

Published: April 9, 2020

Copyright (c) 2020 by author(s) and Scientific Research Publishing Inc. This work is licensed under the Creative Commons Attribution International License (CC BY 4.0).

http://creativecommons.org/licenses/by/4.0/

\begin{abstract}
Epidural analgesia has long been regarded as the gold standard in abdominal surgery. However, concerns regarding risks associated with central neuraxial blockade, catheter placement and the presence of coagulopathy in patients undergoing liver resection have limited its use. Bilateral erector spinae plane blocks and catheter placement may mimic the effects of epidural analgesia by blocking both somatic and visceral pain while concomitantly avoiding central neuraxial blockade and catheter placement. We describe our experience in using the erector spinae plane block and catheter placement as part of a multimodal analgesia approach in a patient undergoing laparoscopic and another patient undergoing open liver resection. Our findings concur with previous reports which suggest that erector spinae plane blocks may be more efficacious as somatic rather than visceral analgesia. However, we conclude that further studies on factors affecting its efficacy should be conducted in view of the present lack of researched evidence.
\end{abstract}

\section{Keywords}

Erector Spinae Plane Block, Bilateral Erector Spinae Plane Block,

Laparoscopic Liver Resection, Open Liver Resection, ESP Block

\section{Introduction}

Opioids have always been the primary modality of pain management in patients undergoing hepatic resection [1]. However, severity of liver cirrhosis and size of liver resection are correlated with impaired opioid metabolism and drug accumulation [2]. While epidural analgesia has long been regarded as the gold standard for abdominal surgery, concerns persist regarding complications associated 
with catheter placement, intra- and post-operative coagulopathy as well as hypotension from sympatholysis necessitating increased perioperative fluid administration [3].

The erector spinae plane (ESP) block was first described by Forero et al. as an effective treatment method for thoracic neuropathic pain [4]. The technique involves administration of local anaesthetic into the interfascial plane deep to the erector spinae muscle. Initial clinical findings suggested that the injectate would spread to both the ventral and dorsal ramus of the spinal nerves to produce blockade of both somatic and visceral pain, allowing bilateral ESP blocks to mimic the effects of epidural analgesia [5] [6]. As the block can be performed at any spinal level unilaterally or bilaterally, there have been reports of its use in a wide range of surgical procedures including thoracic, spine, breast, upper and lower abdominal surgeries [7] [8].

In this report, we describe the use of bilateral ESP blocks in 2 patients undergoing liver resection. The first laparoscopically and the second through a right Kocher's incision with possible midline extension as we note that there have been no previous reports comparing them side-by-side.

\section{Case Report}

\subsection{Case 1}

A 56-year-old gentleman $(168 \mathrm{~cm}, 62 \mathrm{~kg})$ underwent elective laparoscopic wedge resection of liver segment $6 / 7$ and segment 8 for hepatocellular carcinoma. $\mathrm{He}$ was a hepatitis $\mathrm{C}$ carrier with Child's A liver cirrhosis and was on antiviral therapy. An ESP block was offered as part of a multimodal analgesia approach and as an alternative to central neuraxial blockade. A single bolus ESP block was performed on the left T7 level with an $18 \mathrm{~g}$ Touhy needle. $20 \mathrm{mls}$ of $0.4 \%$ Ropivacaine was injected into the plane under ultrasound guidance (Figure 1). Another ESP block was performed on the right T7 level with $20 \mathrm{mls}$ of $0.4 \%$ Ropivacaine followed by catheter insertion which was anchored at $10 \mathrm{~cm}$ with $5 \mathrm{~cm}$ in space.

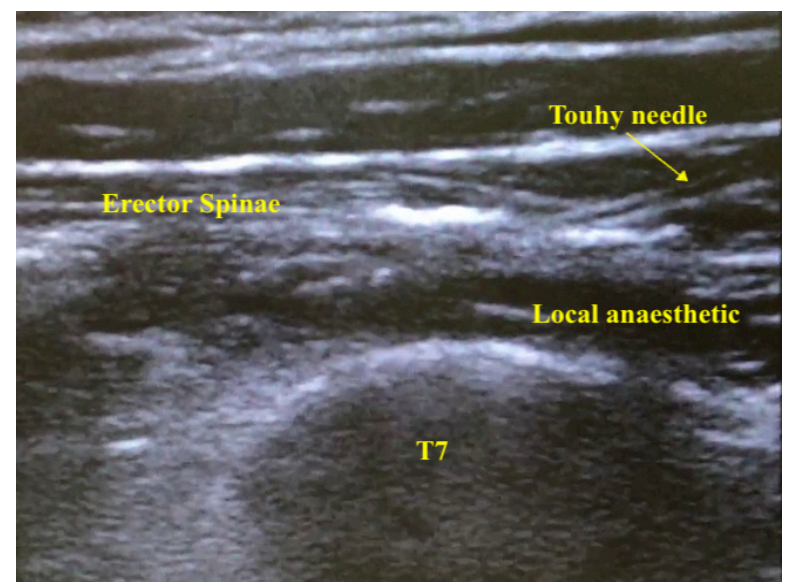

Figure 1. Real-time ultrasound image of the erector spinae plane block with $18 \mathrm{~g}$ Touhy needle in situ. The deposition of local anaesthetic can be seen in the plane between the T7 transverse process and the erector spinae muscle. 
General anaesthesia was then induced and endotracheal tube inserted for surgery which lasted 8.5 hours. Intraoperative analgesia included effect-site target-controlled-infusion of Remifentanil (titrated between 0.5 to $1.0 \mathrm{ng} / \mathrm{ml}$ ), 2 doses of paracetamol $1 \mathrm{gm}$, Fentanyl $100 \mathrm{mcg}$, Ketamine $60 \mathrm{mg}$, Morphine 10 $\mathrm{mg}$. Boluses of $8 \mathrm{mls} 0.4 \%$ Ropivacaine were administered via the ESP catheter at 4-hour intervals (total 2 boluses).

Post-operatively he was started on $5 \mathrm{ml} / \mathrm{hr}$ of $0.2 \%$ Ropivacaine infusion via the ESP catheter and Patient Controlled Analgesia (PCA) Morphine. On post-operative day 1 , he complained of pain score $6 / 10$ on movement to the Acute Pain Service team. $10 \mathrm{mls}$ 0.5\% Ropivacaine bolus was administered via the ESP catheter and his pain score improved to $2 / 10$. He was started on oral analgesia on day 2. PCA Morphine was discontinued and the ESP catheter removed on day 3. The patient was discharged on day 5 with oral Paracetamol, Tramadol and Etoricoxib. Table 1 summarizes his pain management for the first 3 post-operative days.

\subsection{Case 2}

A 67-year-old lady $(156 \mathrm{~cm}, 60 \mathrm{~kg})$ underwent elective open resection of liver segments 4a/8, 2 and 7 for colorectal liver metastasis. She was non-opioid naïve and had anterior resection of sigmoid carcinoma 18 months ago followed by adjuvant chemotherapy. ESP block was offered as part of an opioid sparing multimodal analgesia approach and as an alternative to central neuraxial blockade. ESP blocks were performed on the left and right T7 level with $20 \mathrm{mls} 0.45 \%$ Ropivacaine administered on each side. Catheters were sited after good Ropivacaine spread under the erector spinae muscles were confirmed by ultrasound imaging. The left catheter was anchored at $12 \mathrm{~cm}$ with $4 \mathrm{~cm}$ in space while the right catheter was anchored at $10 \mathrm{~cm}$ with $3 \mathrm{~cm}$ in space (Figure 2).

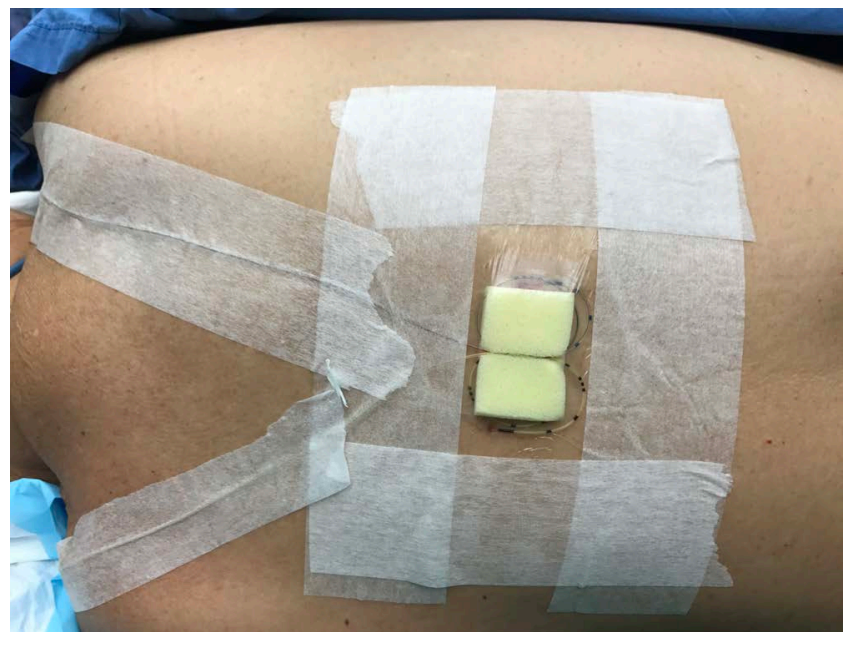

Figure 2. Bilateral erector spinae catheters inserted at the T7 level prior to induction of general anaesthesia. Taping the catheters onto each side of the patient's shoulders avoids subsequent confusion on the laterality of each catheter. 
Table 1. Summary of pain management for case 1.

\begin{tabular}{cccc}
\hline & POD 1 & POD 2 & POD 3 \\
\hline PCA Morphine (mg) & 24 & 15 & 6 \\
ESP Ropivacaine 0.2\% (ml/hr) & 5 & 5 & 5 \\
ESP Bolus 0.5\% Ropivacaine & $10 \mathrm{mls}$ & 0 & 0 \\
Adjuvant analgesia & Nil by mouth & Paracetamol & $\begin{array}{c}\text { Paracetamol } \\
\text { Etoricoxib } \\
\text { Pain score at rest }\end{array}$ \\
Pain score on movement & 0 & 0 & Tramadol \\
& $2-6$ & $2-3$ & 0 \\
& & & $2-3$
\end{tabular}

General anaesthesia was then induced and endotracheal tube inserted for surgery which lasted 6 hours. Intraoperative analgesia included effect-site target-controlled-infusion of Remifentanil (titrated between 0.5 to $2.75 \mathrm{ng} / \mathrm{ml}$ ), Ketamine infusion $5 \mathrm{mg} / \mathrm{hr}$ (total $24 \mathrm{mg}$ ), Tramadol $50 \mathrm{mg}$, Paracetamol $1 \mathrm{gm}$, Fentanyl $75 \mathrm{mcg}$ and Morphine $3 \mathrm{mg}$.

Post-operatively she was started on $4 \mathrm{ml} / \mathrm{hr} 0.2 \%$ Ropivacaine via the right ESP catheter and PCA Morphine. No infusion was started in the left catheter as the surgical incision was not extended to the left or down the midline. On post-operative day 1 , she complained of pain score $5 / 10$ on movement to the Acute Pain Service team. $10 \mathrm{mls}$ 0.5\% Ropivacaine boluses were administered via the left and right ESP catheters and her pain score improved to $2 / 10$. The right ESP catheter infusion rate was increased to $6 \mathrm{ml} / \mathrm{hr}$. She was started on oral analgesia on day 2. PCA Morphine was discontinued and ESP catheters removed on day 3. She was discharged on day 6 with oral Paracetamol and Tramadol. Table 2 summarizes her pain management for the first 3 post-operative days.

\section{Discussion}

Table 3 provides a summary of both cases. Since the first description of bilateral ESP block for post-operative analgesia in laparoscopic ventral hernia surgery [7], bilateral ESP blocks have been described in a myriad of other surgeries including thoracic, breast, abdominal and spine surgeries [8]. Being a relatively new technique, most of these were case reports and case series with a limited number of randomized trials and retrospective studies [8]. Most described its efficacy in pain control and reducing overall opioid requirements. However, none described its use in laparoscopic liver resection. In our report, we present a case of laparoscopic liver resection in a side-by-side comparison with a case of open liver resection.

An immediately evident observation would be the relatively higher opioid requirement in the patient who had laparoscopic surgery especially in post-operative days 1 and 2 . The source and characteristics of pain differ in laparoscopic versus open procedures [6]. In laparoscopic upper abdominal surgeries, peritoneal stretching and irritation by carbonic anhydrase in response to 
Table 2. Summary of pain management for case 2 .

\begin{tabular}{cccc}
\hline & POD 1 & POD 2 & POD 3 \\
\hline PCA Morphine $(\mathrm{mg})$ & 7 & 5 & 0 \\
ESP Ropivacaine 0.2\% (ml/hr) & 4 & 6 & 0 \\
ESP Bolus 0.5\% Ropivacaine & $10 \mathrm{mls}$ (Left) & 0 & Paracetamol Tramadol \\
Adjuvant analgesia & $10 \mathrm{mls}$ (Right) & Paracetamol & 0 \\
Pain score at rest & Nil by mouth & 0 & 0 \\
Pain score on movement & 0 & $2-3$ & \\
\hline
\end{tabular}

Table 3. Summary of the two cases.

\begin{tabular}{|c|c|c|c|c|}
\hline Case & Patient & Operation & Erector spinae block & What we demonstrate \\
\hline 1 & $\begin{array}{l}\text { 56-year-old } \\
\text { gentleman }\end{array}$ & $\begin{array}{l}\text { Laparoscopic wedge } \\
\text { resection of liver } \\
\text { segment } 6 / 7 \text { and } \\
\text { segment } 8 \\
\text { hepatocellular } \\
\text { carcinoma }\end{array}$ & $\begin{array}{l}\text { Indication: } \\
\text { Part of multimodal analgesia pain management } \\
\text { and as an alternative to central neuraxial blockade. } \\
\text { Block performed: } \\
\text { Pre-induction single bolus left ESP block at } \\
\text { T7 level. } \\
\text { Pre-induction right ESP block and catheter } \\
\text { insertion at T7 level. }\end{array}$ & $\begin{array}{l}\text { Bilateral ESP block can be an effective } \\
\text { intra-operative analgesia modality in } \\
\text { laparoscopic liver surgery patients. } \\
\text { Right sided ESP catheter allowed } \\
\text { prolongation of analgesia to the } \\
\text { post-operative period and contributes } \\
\text { to multimodal analgesia approach. }\end{array}$ \\
\hline 2 & $\begin{array}{c}\text { 67-year-old } \\
\text { lady }\end{array}$ & $\begin{array}{l}\text { Open resection of liver } \\
\text { segments } 4 \mathrm{a} / 8,2 \text { and } 7 \\
\text { for colorectal } \\
\text { liver metastasis }\end{array}$ & $\begin{array}{l}\text { Indication: } \\
\text { Part of multimodal analgesia opioid sparing } \\
\text { pain management and as an alternative to } \\
\text { central neuraxial blockade. } \\
\text { Block performed: } \\
\text { Pre-induction right and left ESP block and } \\
\text { catheter insertion at T7 level. }\end{array}$ & $\begin{array}{l}\text { Bilateral ESP blocks can be an effective } \\
\text { opioid sparing analgesia modality in } \\
\text { open liver surgery patients. } \\
\text { The insertion of ESP catheters bilaterally } \\
\text { allows the extension of analgesia effects } \\
\text { post-operatively via continuous local } \\
\text { anaesthetic infusion and intermittent } \\
\text { boluses. }\end{array}$ \\
\hline
\end{tabular}

carbon dioxide insufflation of the parietal peritoneum contributes to the pain response. As such, while unilateral ESP blocks may suffice in open surgeries, bilateral ESP blocks should be performed in laparoscopic procedures [8].

Another possible explanation for the difference in opioid consumption between the cases could be the extent of liver resection and the resultant visceral pain. The laparoscopic procedure was longer and had a larger segment of liver resected. Though somatic pain constitutes $70 \%-75 \%$ of pain and lasts for 72 hours following open surgery, visceral pain is usually more intense albeit short lived lasting for 24 - 36 hours [9]. Chin et al. reported that the ESP block is able to provide visceral analgesia in patients undergoing ventral hernia repair [5]. However other authors have found that while ESP blocks provide effective somatic analgesia and have definite opioid sparing effect following abdominal surgery, its visceral analgesia effects may be less efficacious [9] [10].

While there were no absolute contraindications to the insertion of epidural catheters in our patients, derangement of coagulation markers post hepatic resection are common and are correlated to the extent of resection [1]. Though often self-limiting, post-operative coagulopathy peaks on days 2 - 5, coinciding with when epidural catheters need to be removed. Moreover, epidural catheter 
placement is usually performed via landmark technique without ultrasonography guidance. It is associated with all the inherent risks of central neuraxial techniques such as inadvertent dural or vascular puncture, epidural abscess and haematoma risks. The resultant sympatholysis may also compound the haemodynamic instability in major liver surgeries.

At present, ESP blocks offer a viable alternative as part of the multimodal analgesia toolkit in managing post hepatic resection pain. The blocks can be performed under real-time ultrasonographic guidance to visualize adequate spread of local anaesthetic within the plane and reduce risk of complications. Catheter placement allows the prolongation of analgesic effects to the post-operative period. Its reported ability to provide both somatic and visceral analgesia [5] [6] offers advantages over other alternative techniques such as subcostal and transversus abdominus plane blocks which only provide somatic analgesia.

\section{Conclusion}

Our experience corroborates with previous reports which showed that bilateral ESP blocks reduce opioid consumption when used as part of a multimodal analgesia approach [8]. Similar to previous reports, ESP blocks also appear to be more efficacious for somatic analgesia and less so for visceral analgesia [9] [10]. Although there have been reports of block failure and lack of efficacy [11] [12], there is currently insufficient research into factors that may affect this such as the optimal volume, concentration and rate of local anaesthetic administration, level of catheter placement and factors related to patient or case selection. When performed at the T7 level, Chin et al. [5] [7] suggested that local anaesthetic spread occurs from the upper thoracic to L2 - 3 levels. Hence, ESP blocks show potential for wide applicability from thoracic to upper and lower abdominal surgery. As such, we advocate for more studies into this promising technique.

\section{Consent for Publication}

Informed consent was obtained from all patients.

\section{Availability of Data and Materials}

Data sharing is not applicable to this article as no datasets were generated or analysed during the current study.

\section{Authors' Contributions}

JGCL, KLW and PAS recruited, consented and managed the patients.

JGCL and AWH wrote the manuscript.

All authors read and approved the manuscript.

\section{Conflicts of Interest}

The authors have no conflicts of interest to declare regarding the publication of this paper. 


\section{References}

[1] Wrighton, L.J., O’Bosky, K.R., Namm, J.P. and Senthil, M. (2012) Postoperative Management after Hepatic Resection. Journal of Gastrointestinal Oncology, 3, 41-47. https://doi.org/10.3978/j.issn.2078-6891.2012.003

[2] Rudin, A., Lundberg, J.F., Hammarlund-Udenaes, M., Flisberg, P. and Werner, M.U. (2007) Morphine Metabolism after Major Liver Surgery. Anesthesia \& Analgesia, 104, 1409-1414. https://doi.org/10.1213/01.ane.0000261847.26044.1d

[3] Agarwal, V. and Divatia, J. (2019) Enhanced Recovery after Surgery in Liver Resection: Current Concepts and Controversies. Korean Journal of Anesthesiology, 72, 119-129. https://doi.org/10.4097/kja.d.19.00010

[4] Forero, M., Adhikary, S.D., Lopez, H., Tsui, C. and Chin, K.J. (2016) The Erector Spinae Plane Block: A Novel Analgesic Technique in Thoracic Neuropathic Pain. Regional Anesthesia \& Pain Medicine, 41, 621-627. https://doi.org/10.1097/AAP.0000000000000451

[5] Chin, K.J., Malhas, L. and Perlas, A. (2017) The Erector Spinae Plane Block Provides Visceral Abdominal Analgesia in Bariatric Surgery: A Report of 3 Cases. Regional Anesthesia \& Pain Medicine, 42, 372-376. https://doi.org/10.1097/AAP.0000000000000581

[6] Tulgar, S., Selvi, O., and Kapakli, M.S. (2018) Erector Spinae Plane Block for Different Laparoscopic Abdominal Surgeries: Case Series. Case Reports in Anesthesiology, 2018, Article ID: 3947281. https://www.hindawi.com/journals/cria/2018/3947281/ https://doi.org/10.1155/2018/3947281

[7] Chin, K.J., Adhikary, S., Sarwani, N. and Forero, M. (2017) The Analgesic Efficacy of Pre-Operative Bilateral Erector Spinae Plane (ESP) Blocks in Patients Having Ventral Hernia Repair. Anaesthesia, 72, 434-438. https://doi.org/10.1111/anae.13814

[8] Tulgar, S., Ahiskalioglu, A., De Cassai, A. and Gurkan, Y. (2019) Efficacy of Bilateral Erector Spinae Plane Block in the Management of Pain: Current Insights. Journal of Pain Research, 12, 2597-2613. https://doi.org/10.2147/JPR.S182128

[9] Tariq, Z. and Niraj, G. (2018) Continuous Erector Spinae Plane (ESP) Analgesia in Different Open Abdominal Surgical Procedures: A Case Series. Journal of Anesthesia and Surgery, 5, 57-60. https://doi.org/10.15436/2377-1364.18.1853

[10] Restrepo-Garces, C.E., Chin, K.J., Suarez, P., et al. (2017) Bilateral Continuous Erector Spinae Plane Block Contributes to Effective Post-Operative Analgesia after Major Open abdominal Surgery: A Case Report. A \& A Practice, 9, 319-321. https://doi.org/10.1213/XAA.0000000000000605

[11] Luis-Navarro, J.C., Seda-Guzmán, M., Luis-Moreno, C. and Chin, K.-J. (2018) Erector Spinae Plane Block in Abdominal Surgery: Case Series. Indian Journal of Anaesthesia, 62, 549-554. https://doi.org/10.4103/ija.IJA_57_18

[12] Tulgar, S., Selvi, O., Senturk, O., Serifsoy, T.E. and Thomas, D.T. (2019) Ultrasound-Guided Erector Spinae Plane Block: Indications, Complications, and Effects on Acute and Chronic Pain Based on a Single-Center Experience. Cureus, 11, e3815. https://doi.org/10.7759/cureus.3815 